\title{
Seismic Behavior of Medium and High Strength Concrete Buildings
}

\author{
J.M. Bairán, R. Moreno-González* and J. Peguero
}

Universitat Politecnica de Catalunya. C/Jordi Girona, 1-3. E.T.S.E.C.C.P.B. Mod.C1, ofic.201, Campus Nord. Barcelona, Spain

\begin{abstract}
Current concrete technology has made higher concrete grades more affordable to mid and high-rise buildings; hence its use has been increasing in the late years as it allows for smaller cross-sections, reduction of the structure's weight, improve durability, among other benefits. However, it is known that brittleness of plain concrete increases with the strength; therefore, some national codes have limited the concrete's strength in high seismic zones.

In this paper, the seismic behavior of a 10 storey dual frame-wall building, designed with concrete grades C30, C60 and C90 is studied in order to assess the advantages and disadvantages of this material and investigate the effects of high concrete strength on the seismic behavior of buildings. In total, three models were studied. Furthermore, a comparison between Force-Based-Design (FBD) and Displacement-Based-Design (DBD) methodologies is made. DBD showed advantages in determining the adequate design ductility and the distribution of forces between frame and wall.

The structures are designed according to Eurocode 8 for seismic design high ductility structures. To assess the seismic performance of the building, pushover analyses were made according to the Eurocode 8 (N2 method) in order to determine the performance point.

It is observed that adequate design could accommodate concrete's reduction of ductility. Needed confinement levels can objectively be defined for different concrete strength. Some benefits of the overall increase of strength are highlighted in the paper. The $\mathrm{C} 90$ building showed adequate response, although changes on the failure mode were observed.
\end{abstract}

Keywords: Concrete buildings, displacement-based-design, force-based-design, high strength concrete, pushover analysis, seismic behavior, seismic design.

\section{INTRODUCTION}

In recent years the use of high strength concrete (HSC) has become very common in bridges, buildings and some marine structures due to its benefits in terms in increasing strength, durability and stiffness, allowing for larger spans and weight reduction. In the case of buildings, the use of HSC is determinant in elements in compression, as columns, where concrete strength plays a major role in the element's capacity and ductility.

The first uses of HSC in building columns date from the late 60's decade in Chicago (USA), where it was used as a mean to reduce weight in order to minimize the load transmitted to the foundations in sites with very unfavorable soil properties. Now at days, its use has been generalized. In high-rise buildings concrete strength larger than $100 \mathrm{MPa}$ has been used. In the late 80 's decade and at the beginning of the 90's decade several prominent HSC structures were constructed: in Seattle, a $220 \mathrm{~m}$ building was constructed using $115 \mathrm{MPa}$ concrete. In Norway and UK, large amount of HSC

*Address correspondence to this author at the Universitat Politecnica de Catalunya. C/Jordi Girona, 1-3. E.T.S.E.C.C.P.B. Mod.C1, ofic.201. Campus Nord. 08034, Barcelona, Spain; Tel: +(34) 934017351;

Fax: +(34) 934054135; E-mail: mgrosangel@gmail.com was used in construction of large off-shore structures. In Spain, the first use of HSC was two slender footbridges with $80 \mathrm{MPa}$ concrete, in Montjüic, constructed for the 1992 Olympic Games.

In spite of these main benefits, it is known that HSC is more brittle than regular concrete; hence, its use in high seismic zones has been less extended. Because of its brittleness, some national construction codes ban the use of HSC in high seismic zones; e.g. the Algerian seismic codes [1] limit the concrete strength in seismic zones to $45 \mathrm{MPa}$.

This paper aims at investigating the effects of concrete strength and design methods in the seismic behavior of concrete buildings. A 10 stories building dual frame-wall located high seismic zone was design and detailed considering different concrete grades representative of normal, medium and high strength. The buildings are designed considering force and displacement based methodologies and detailed following the ductility requirements of Eurocode 8 [2]. The seismic behavior of the different specimens is evaluated by non-linear pushover analysis for which adequate simulation of the different concrete characteristics, including confinement, was considered. The results are compared and conclusions are presented in terms of design recommendations and observer failure modes. 


\section{CONCRETE CHARACTERISTICS FOR CONFINED HIGH STRENGTH CONCRETE}

Several models to describe the confined characteristics of concrete exist in literature. One of the most extended is due to Mander et al. [3]. This model is well established and has been the basis of design and evaluation codes, such as [4-7]. However, this model was calibrated with normal strength concrete and it has been reported that it may provide results in the unsafe side for HSC. Moreover, it has been reported that confined models of normal concrete do not offer good representation of the behavior of HSC [8].

On the other hand, Eurocode 2 [9] include a relatively simple formulation for confined concrete that has not explicit application restriction to in range of concrete grades considered in the code, namely concrete strength from $20 \mathrm{MPa}$ to $90 \mathrm{MPa}$. In this model, the confined strength of concrete $\left(f_{\text {ck,c }}\right)$ is evaluated through Equations (1) and (2), depending on the effective confinement pressure $(\sigma 2)$.

$$
\begin{aligned}
& f_{c k, c}=f_{c k}\left(1+5 \frac{\sigma_{2}}{f_{c k}}\right) \leftarrow \sigma_{2} \leq 0.05 \mathrm{f}_{c k} \\
& f_{c k, c}=f_{c k}\left(1.125+2.5 \frac{\sigma_{2}}{f_{c k}}\right) \leftarrow \sigma_{2}>0.05 \mathrm{f}_{\mathrm{ck}}{ }_{\mathrm{k}}
\end{aligned}
$$

After determining the confined strength all other parameters of the stress-strain $(\sigma-\varepsilon)$ curve can be computed as function of this variable. Therefore, the strain at peak load $\left(\varepsilon_{\mathrm{c}, \mathrm{c}}\right)$ and ultimate strain $\left(\varepsilon_{\mathrm{cu}}\right)$ can be obtained from Equations (3) and (4), respectively.

$$
\begin{aligned}
& \varepsilon_{c, c}=\varepsilon_{c}\left(\frac{f_{c k, c}}{f_{c k}}\right)^{2} \\
& \varepsilon_{c u, c}=\varepsilon_{c u}+0.2 \frac{\sigma_{2}}{f_{c}}
\end{aligned}
$$

One inconvenient of this model is that the effective confinement pressure is supposed to be symmetrical in orthogonal directions, which is not generally the case if transversal steel ratio is not identical in the two directions. In this case, in this paper the mean lateral pressure, $0.5(\sigma y+\sigma z)$, is considered to define a cylindrical stress state in which the previous model can be applied. Therefore, the effective confined pressure $\left(\sigma_{2}\right)$ will be computed as, Equation (5):

$\sigma_{2}=\frac{1}{2} \alpha \frac{V_{s t}}{V_{c}} \frac{f_{y t}}{f_{c}}=\frac{1}{2} \alpha \omega$

where,

$\omega=\frac{V_{s t}}{V_{c}} \frac{f_{y t}}{f_{c}}$

$\alpha$ is an efficiency factor taking into account three former aspects. Namely, the concrete strength, the distance of the longitudinal reinforcement that is effectively lateral supported by means of transversal reinforcement and the spacing between lateral reinforcements.

Before applying this model in the current study, it is compared against experimental data for validation purposes. To this extent, the experimental data reported by Sharma et al. [10] on concrete strength ranging from $62 \mathrm{MPa}$ to 84 $\mathrm{MPa}$ and different confinement ratios are compared against the model's predictions. Figs. (1 and 2) show the comparison of the confined concrete characteristics considered predicted by the modified EC2 [9] model and the experimental observation. It can be seen that the model is biased towards the safe side both for the confined strength and predicted strains. However, the strength bias seems uniform with the concrete strength while it increases in the case of confined strength. A reason for this may be found in the different dilatancy characteristics of high strength concrete with respect to normal concrete, as recently demonstrated in Osorio et al. [11]. Further research in this respect is required.

The constitutive model for concrete, confined and unconfined that will be used in this study is shown in equations (79). This set of equations is defined in terms of the peak strength, the elastic modulus $\left(\mathrm{E}_{\mathrm{cm}}\right)$, and the strain at peak load and failure. In the case of confined concrete, the elastic modulus is taken the same as for un-confined, as large lateral

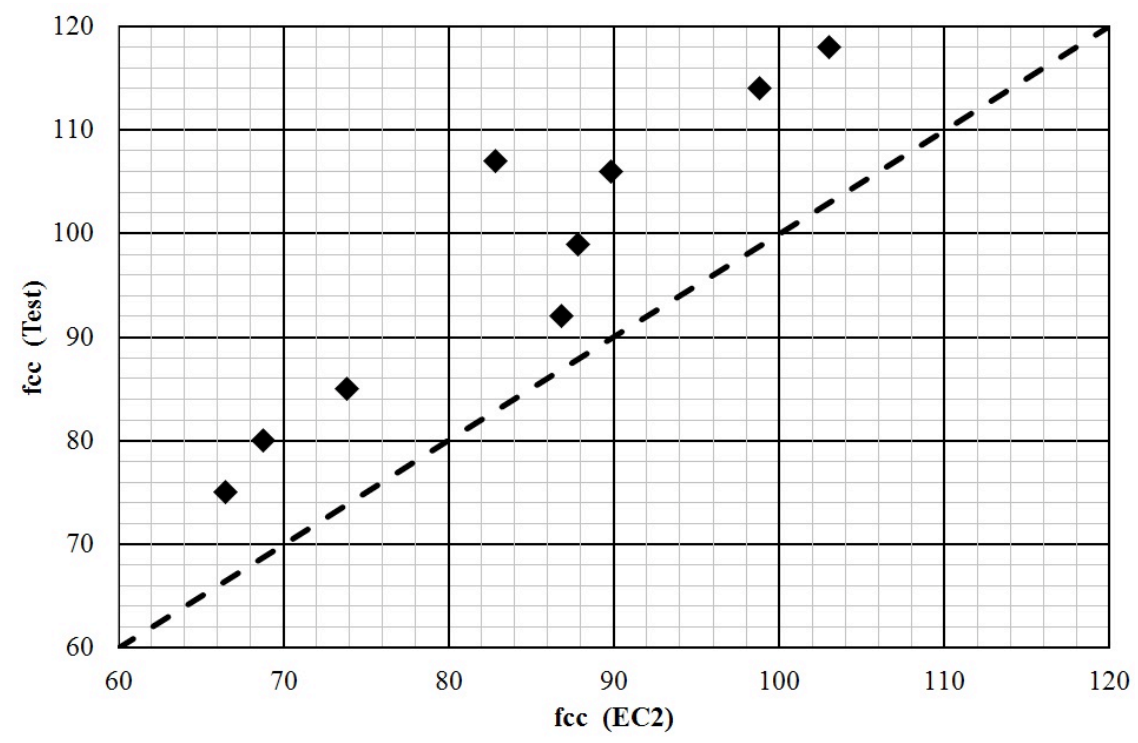

Fig. (1). Comparison between experimental and predicted confined strength (MPa). 


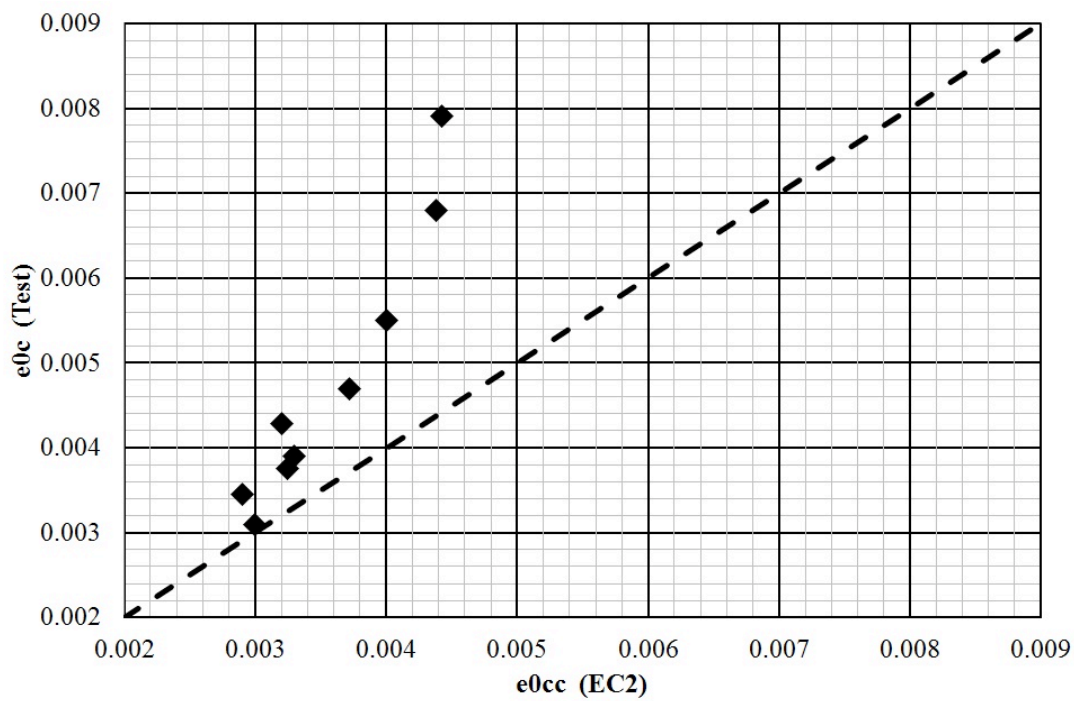

Fig. (2). Comparison between experimental and predicted peak confined strain.

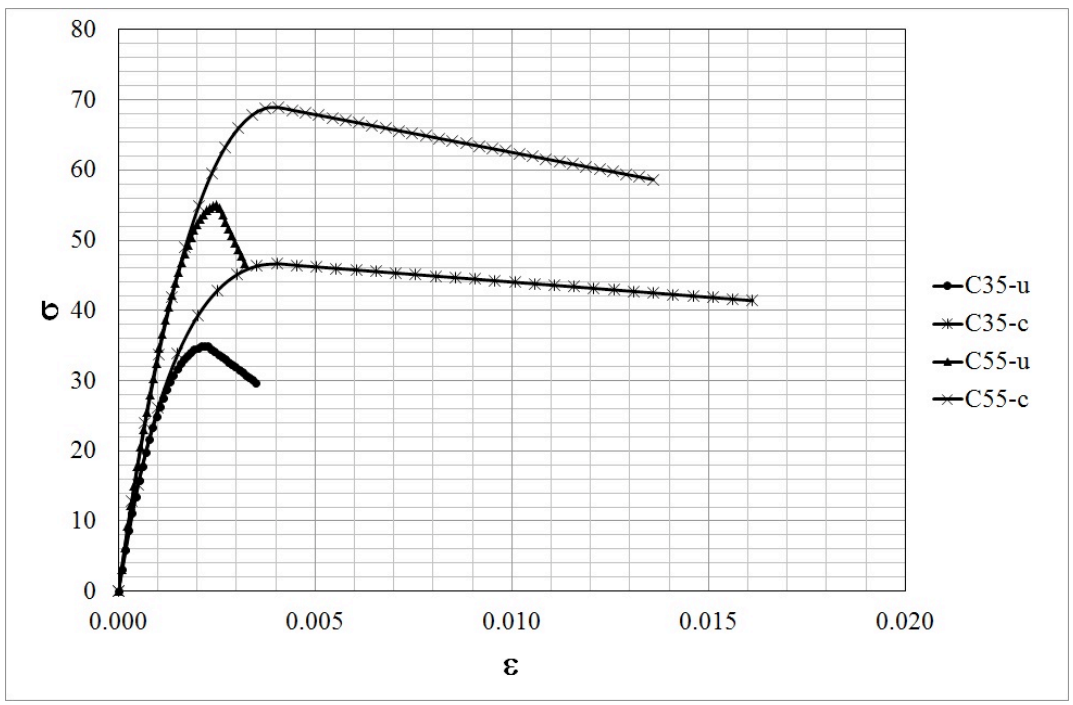

Fig. (3). Comparison of unconfined and confined $\sigma-\varepsilon$ curves for two different concrete grades according to the used model (MPa).

strains due to dilatancy, that activates confinement pressure in stirrups, mainly take place when strains approaches the peak load. Parameters $\mathrm{f}_{\mathrm{cc}}, \varepsilon_{\mathrm{cc}}, \varepsilon_{\mathrm{cu}}$ are computed according to equations (1-6).

$\sigma=f_{C}\left[\frac{k\left(\varepsilon / \varepsilon_{c}\right)-\left(\varepsilon / \varepsilon_{c}\right)^{2}}{1+(k-2)\left(\varepsilon / \varepsilon_{c}\right)}\right] \leftarrow \varepsilon \leq \varepsilon_{C}$

$k=1.05 E_{c m} \frac{\varepsilon_{c}}{f_{c}}$

$\sigma=f_{c}-\left(\frac{0.15 f_{c}}{\varepsilon_{c u}-\varepsilon_{c}}\right)\left(\varepsilon-\varepsilon_{c}\right) \leftarrow \varepsilon>\varepsilon_{c}$

Fig. (3) compares the $\sigma-\varepsilon$ resulting from this model for two different concrete grades for confined and unconfined cases.

\section{DESCRIPTION OF THE STRUCTURE AND SEISMIC ACTION}

The analysed structure is a 10 stories building, $31 \mathrm{~m}$ height, dual frame-wall building. Fig. (4) shows a lateral view of a representative. The structure is regular and symmetric in the two directions. The floor system consists of waffle slabs supported by beams in the two directions, providing a rigid diaphragm in each storey. Moreover, torsion effects are considered negligible. Therefore, in this study, only the representative frame is analysed.

In order to determine the effects of the concrete grade, the dual frame-wall system is designed using three different types of concrete: $30 \mathrm{MPa}, 60 \mathrm{MPa}$, and $90 \mathrm{MPa}$, which are representative of normal, mid and high strength concrete. The structures will be designed using a Displacement-BasedDesign (DBD) approach to determine the internal forces that satisfy the design spectrum. However, the internal forces and deformation obtained from a traditional Force-Based-Design Method (FBD) will also be investigated and discussed in order to compare the influence of the design hypotheses.

The FBD method determines the elastic shear force and its distribution in the structure based on the linear stiffness and the elastic acceleration spectrum. The forces are reduced in a second by a ductility factor, which are tabulated for 


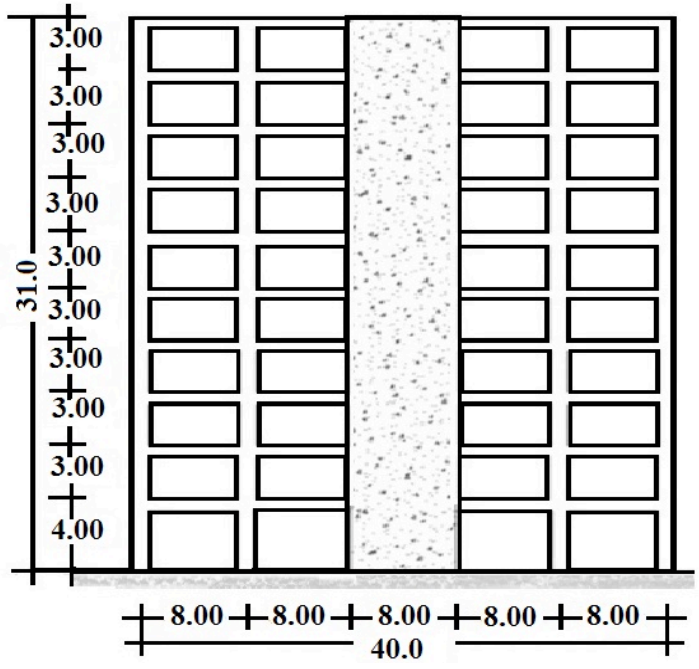

Fig. (4). Geometry of the model (m).

different structural types, to take into account the structure dissipation of forces and less stiffness in non-linear regime. Therefore, this method focuses on the structure resistance.

On the other hand, the DBD starts the design process by determining the maximum displacement level at which the structure should work under, this value defines the inelastic stiffness and ductility in each element, hence there is no need of selecting tabulated ductility reduction factors as it results from the own design process. More details on the DBD method can be found in Priestley at al. [4]. This method al- lows for a more objective design in terms of required ductility and well as a more flexibility in the design assumptions. For example, the distribution of the shear forces resisted by the wall and the frame may be varied depending on the strength and ductility of the two components, while in the FBD they are defined by the elastic stiffness. Therefore, in order to optimize the design, the distribution of seismic shear force between frame and wall are varied according in the DBD method.

The gravity actions considered in the study are listed in Table 1. On the other hand, the seismic action was defined according to Eurocode 8 [2] for a with a peak ground acceleration (PGA) of $0.4 \mathrm{~g}$ and soil type C. Type I acceleration spectrum was used. In Fig. (5), the elastic response spectrum is presented. The building was design for ductility class high (DCH).

In order to determine the design forces in the structure, an elastic multi-modal analysis is carried out considering enough modes to mobilize more than $90 \%$ of the structure's mass. In the FBD method, the modal forces and displacements are combined using the CQC method, which determines the relative forces resisted by the shear wall and the frame. The structural analysis was carried out using SAP2000 software, version 14 [12].

In the DBD method, a relative load factor of $\beta_{F}=0.30$ is used; therefore, the wall is designed to resist $70 \%$ of the shear force and the frame $30 \%$. With this distribution, the frame is designed for higher shear force than in the FBD. The displacement spectrum was obtained from the accelera-

Table 1. Gravity loads.

\begin{tabular}{|c|c|c|}
\hline Loads & Dead Loads & Live Loads \\
\hline \hline Floor (weight, $\mathrm{t}=30+7 \mathrm{~cm}$ ), Stories: $1-9$ & $6.30 \mathrm{kN} / \mathrm{m}^{2}$ & $5.00 \mathrm{kN} / \mathrm{m}^{2}$ \\
\hline Total & $44.10 \mathrm{kN} / \mathrm{m}$ & $35.00 \mathrm{kN} / \mathrm{m}$ \\
\hline 10th Storey Floor & $4.70 \mathrm{kN} / \mathrm{m}^{2}$ & $1.00 \mathrm{kN} / \mathrm{m}^{2}$ \\
\hline Total & $32.90 \mathrm{kN} / \mathrm{m}$ & $7.00 \mathrm{kN} / \mathrm{m}$ \\
\hline
\end{tabular}

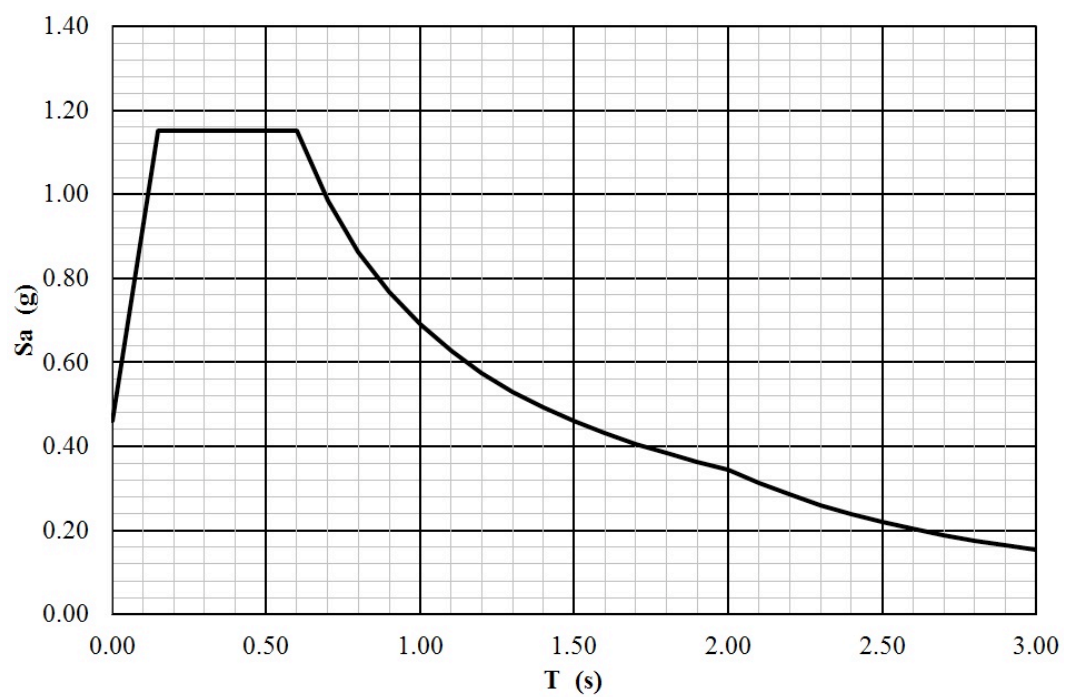

Fig. (5). Elastic design spectrum. 
tion spectrum by means of the following relationship between spectral acceleration $(\mathrm{Sa})$, spectral displacement $(\mathrm{Sd})$ and structural period $(\mathrm{T})$, equation 10 :

$S_{d}=\frac{T^{2}}{4 \pi^{2}} S_{a}$

\section{COMPARISON BETWEEN FORCE-BASED DESIGN AND DISPLACEMENT-BASED-DESIGN METHOD- OLOGIES}

In this section, a comparison of the structures designed according to the FBD and DBD methods are presented in order to determine the more adequate design methodology. In the FBD method, the force distribution is based on the elastic stiffness of the elements. Therefore, it is expected that the shear wall resists most part of the shear base shear. On the other hand, the DBD allows the designer to select the base shear factor that determines the fraction of the base shear resisted by the frame with respect to the shear wall.

Among the parameters that will allow comparing the behavior of the different models, the interstorey drift and the distribution of base shear between wall and frame were selected. Table 2 shows the results in the $1^{\text {st }}$ storey columns obtained after the analysis of the structures design with the two methods and the effects of the design assumptions, while Fig. (6) shows the base-shear forces.

On the other hand, Fig. (7) shows the interstorey drifts distributions for the two cases, defined as the difference between the horizontal displacements of two consecutive stories divided by the storey height (dimensionless quantity). It is observed that the interstorey drifts in the FBD exceed the maximum allowable value in Eurocode 8 [2] (2\%), which means that resizing of the elements is required to satisfy damage control criterion. However, this was not carried out in this study as the main objective of the study was to investigate the effects of concrete strength in the capacity of developing the required ductility.

In the case of DBD, the interstorey drifts are considerably smaller and satisfy the limited values considered in the design, demonstrating that the method is represents a more adequate approach for satisfying damage control.

After the results of this comparative study, the DBD method is selected as more adequate for designing this structure, as it provides a more adequate mean for controlling the interstorey drifts. Secondly, it allows the dual system to behave as such, exploiting better the characteristics of both wall and frame.

Table 2. Distribution of the base shear in $1^{\text {st }}$ storey columns and wall with FBD and DBD methods.

\begin{tabular}{|c|c|c|c|c|}
\hline Case 2= 60MPa & \multicolumn{2}{|c|}{ FBD Method } & \multicolumn{2}{c|}{ DBD Method } \\
\hline Column & Shear, V (kN) & V (\%) & Shear, V (kN) & V (\%) \\
\hline \hline C5 Ext. I & 11.9 & 0.37 & 410.86 & 7.50 \\
\hline C5 Int. I & 29.47 & 0.91 & 410.86 & 7.50 \\
\hline Wall & 3162.14 & 97.45 & 3834.72 & 7.00 \\
\hline C5 Int. J & 29.47 & 0.91 & 410.86 & 7.50 \\
\hline C5 Et. J & 11.9 & 0.37 & 100 & 5478.16 \\
\hline Vbase & 3244.88 & & & 100 \\
\hline
\end{tabular}

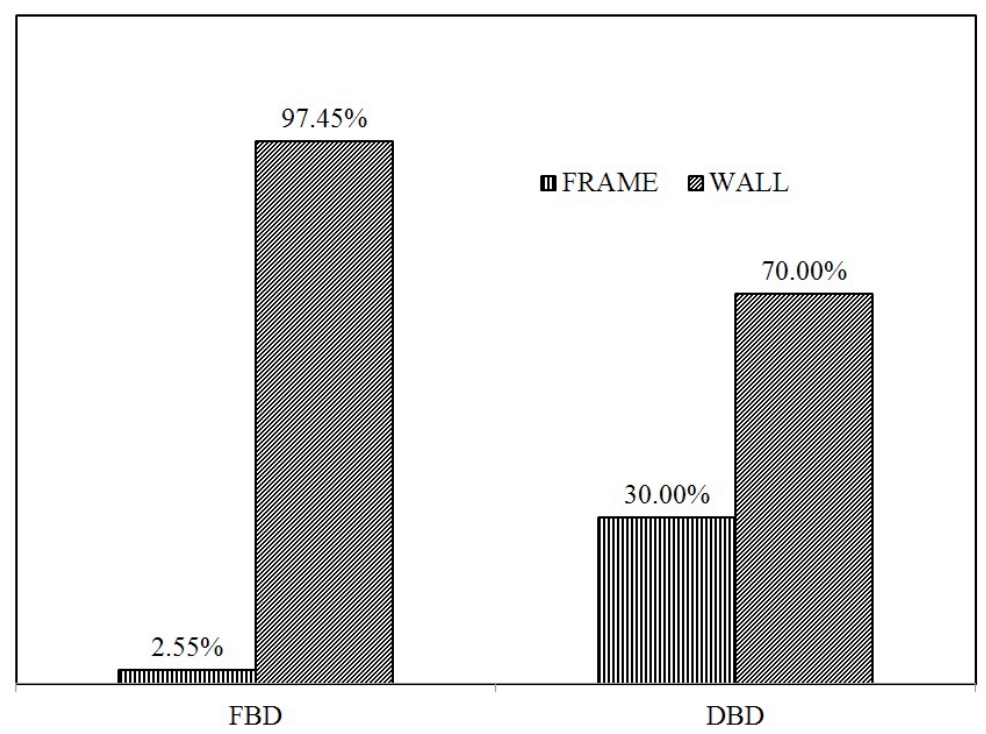

Fig. (6). Distribution of the base shear Frame and Wall with FBD and DBD methods. 

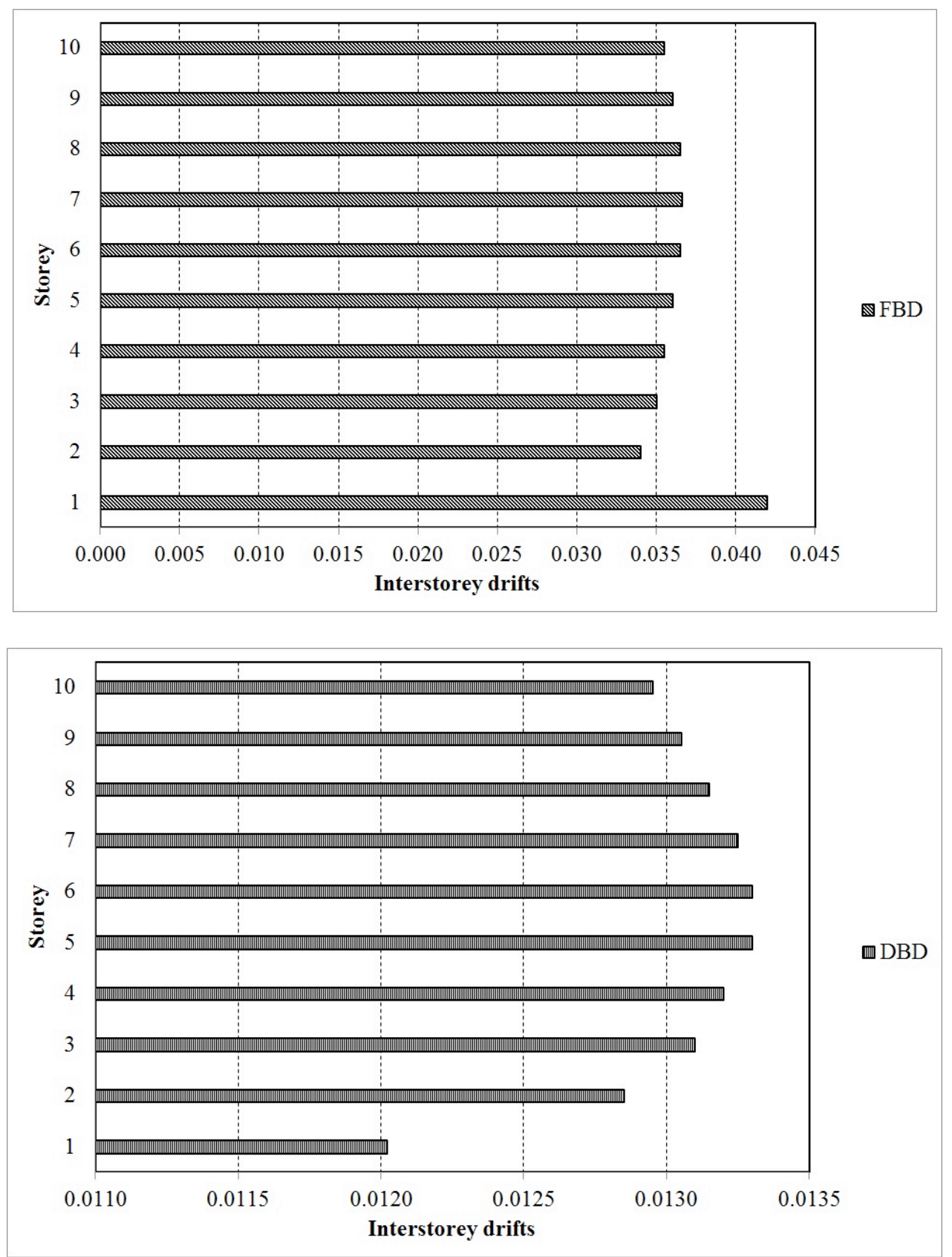

Fig. (7). Interstorey drifts according designs methods: a) FBD, b) DBD.

\section{STRUCTURAL DESING FOR THE DIFFERENT CONCRETE GRADES STRUCTURES}

In this section, the design of the structures according to the DBD will be presented considered a distribution of shear forces of 70/30 between the wall and the frame, respectively. The approach consisted in defining a target displacement that is compatible with the desired maximum drift in the structure. This displacement is directly related to the ductility demand; hence, it allows defining an equivalent damping coefficient which be applied to the elastic spectrum. The design internal forces are obtained objectively without any ductility behavior factor.

Once the internal forces are determined, the element reinforcements are designed following Eurocode 2 [9] and Euro- code 8 [2] provisions. Tables 3-5 summarize the reinforcement layouts in the frame elements and wall considered for the seismic evaluation.

\section{SEISMIC ASSESSMENT PUSHOVER ANALYSIS.}

In order to assess the structure under seismic action, the non-linear static analysis (Pushover) approach was used. The capacity curve and performance point were determined following the procedure described in Eurocode 8 (2\%). Capacity curves were obtained using SAP2000 v14 [12] by means of a lumped inelasticity structural model. The MomentRotation properties of each hinge were obtained using BCSEC program [13] following the concrete constitutive model above described, including confinement reinforcement. 
Table 3. Designed reinforcement for $\mathrm{fc}=30 \mathrm{MPa}$.
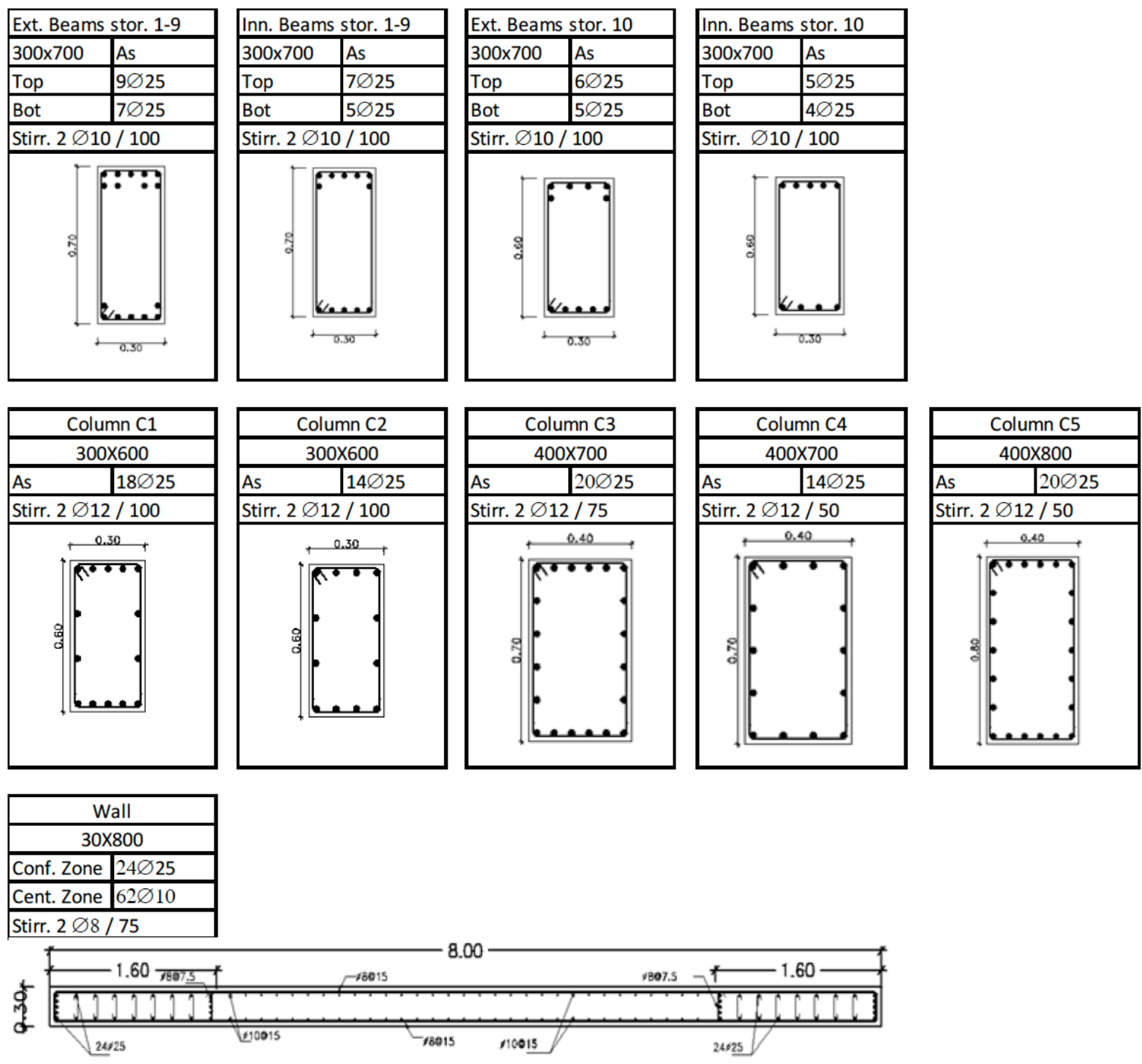

The capacity curves for all cases are shown in Fig. (8). It can be seen that the top displacement and maximum base shear obtained are smaller for smaller concrete strength. In the same manner, the design with $90 \mathrm{MPa}$ shows stiffer response than the other 2 cases. The cases of normal and mid strength concrete, $30 \mathrm{MPa}$ and $60 \mathrm{MPa}$ respectively, show similar response up to a base shear of $6000 \mathrm{kN}$, after this point a more ductile response of the $30 \mathrm{MPa}$ case is evidenced.

In order to apply the Eurocode 8 [2] method to obtain the performance point, the capacity curves are represented as a bilinear elasto-plastic curve. These curves are defined in a way that they are energetically equivalent to the original capacity curves while presenting a single yielding point. The performance points for each case are depicted in Fig. (9). Table 6 shows the numerical values of the performance points. The reduction of ductility capacity is evident in as the concrete strength increases. However, this is not directly traduced to a less seismic capacity as this is partially compensated by increasing the base shear demand. As noted in Table 6, the ratio between the elastic and non-linear seismic force is reduced. It is evident that the DBD design approach is capable of providing enough ductility in the $90 \mathrm{MPa}$ concrete case.

Where Dy and Fy* are the yielding displacement and force, respectively; $\mathrm{Dt}$ is the target displacement, $\mathrm{Sd}\left(\mathrm{Te}^{*}\right)$ and $\mathrm{Sa}\left(\mathrm{Te}^{*}\right)$ are the coordinates of the performance point in spectral coordinates; $\mathrm{k}^{*}$ is the equivalent stiffness of the system; $\mathrm{T}^{*}$ is the fundamental period. The value q represent the computed force reduction factor with respect to an elastic linear system.

The base shear distribution in the dual system, between frame and wall in the dual, are compared in Fig. (10) at the Performance-Point displacement. It is noted that the normal concrete specimen reproduces the design assumed distribution (30/70). However, as concrete strength increases, the frame's participation tends to be larger, reaching up to $46 \%$ in the case of HSC.

Fig. (11) shows the failure mode and critical element position for the three specimens. In the case of normal concrete, the first plastic hinge reaching its ductility capacity is 
Table 4. Designed reinforcement for $\mathrm{fc}=60 \mathrm{MPa}$.
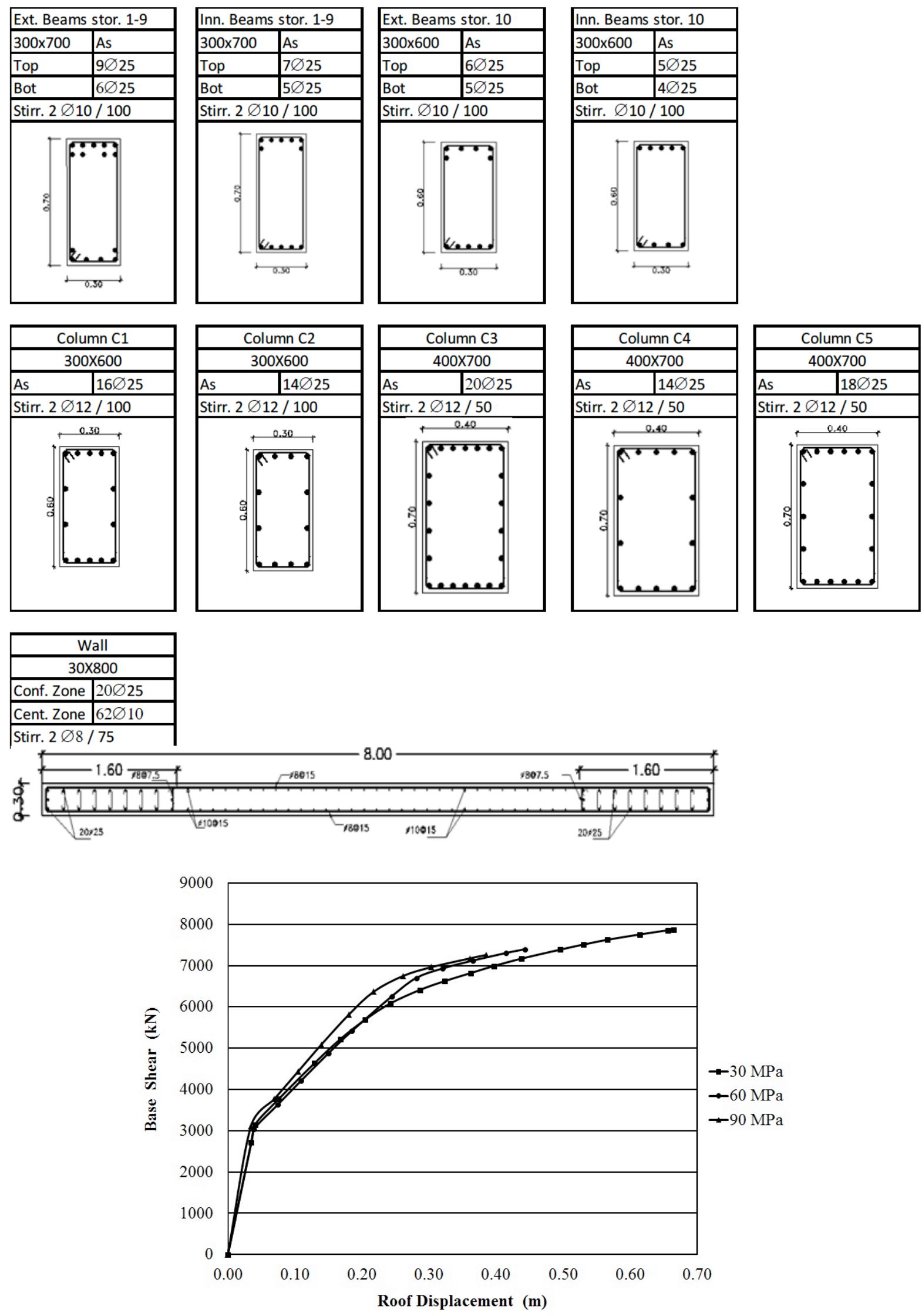

Fig. (8). Capacity curve for the cases of strength 30-60-90 MPa. 
Table 5. Designed reinforcement for $\mathrm{fc}=90 \mathrm{MPa}$.
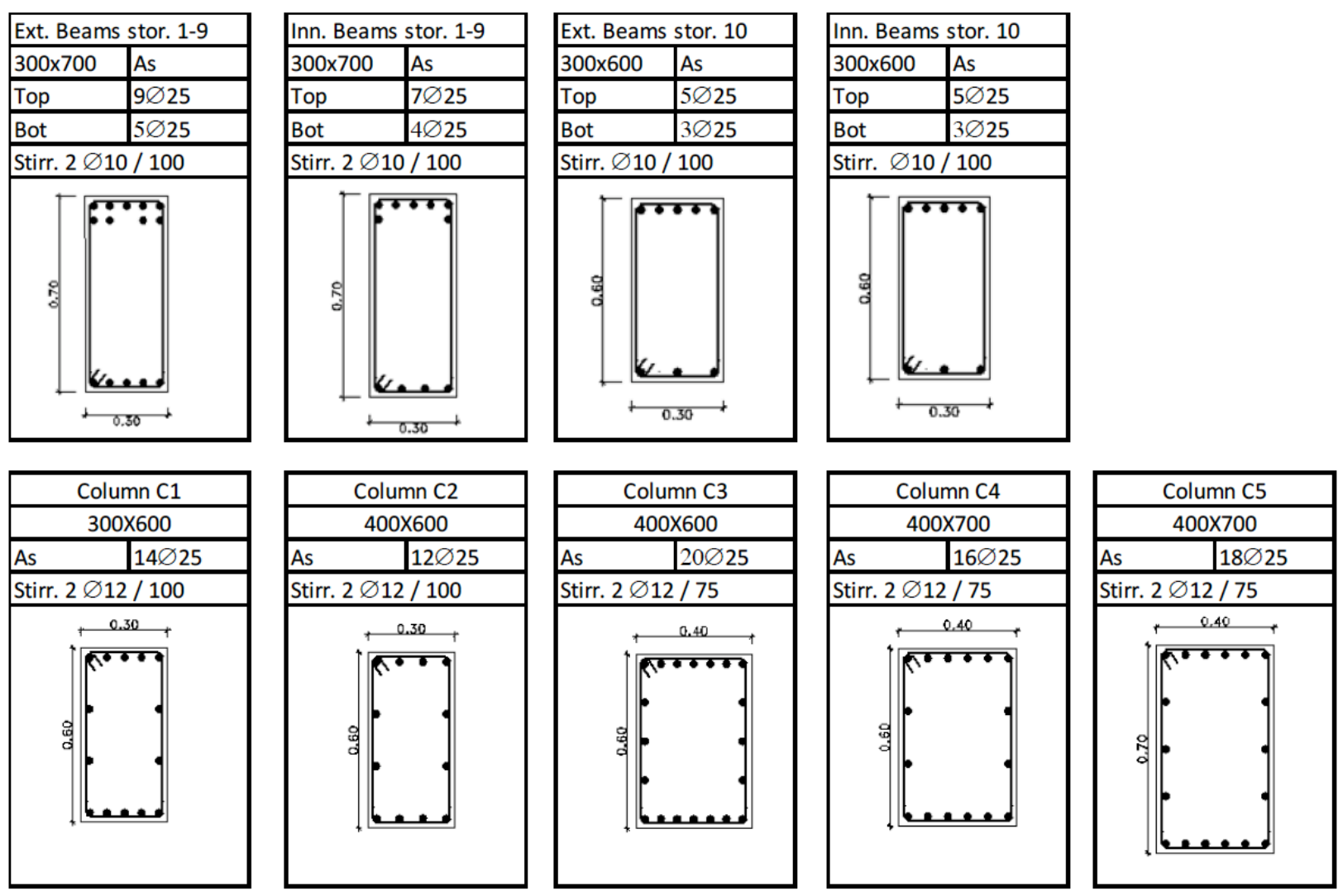

\begin{tabular}{|l|l|}
\hline \multicolumn{2}{|c|}{ Wall } \\
\hline \multicolumn{2}{|c|}{$30 \times 800$} \\
\hline Conf. Zone & $20 \varnothing 25$ \\
\hline Cent. Zone & $62 \varnothing 10$ \\
\hline Stirr. 2 $\varnothing 8 / 75$ \\
\hline
\end{tabular}

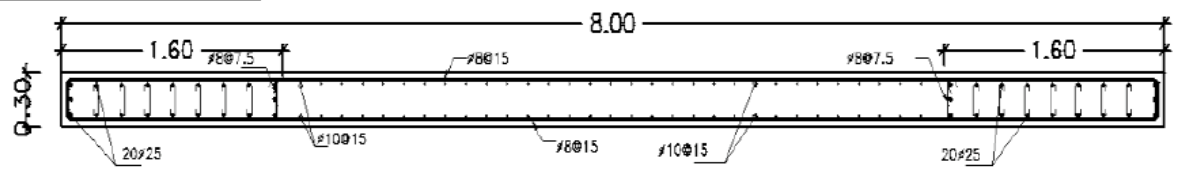

Table 6. Performance-Point characteristics of the three case studies.

\begin{tabular}{|c|c|c|c|}
\hline & C30 & C60 & C90 \\
\hline \hline $\mathrm{Dy}(\mathrm{m})$ & 0.137 & 0.146 & 4806.1 \\
\hline $\mathrm{Fy}(\mathrm{kN})$ & 4637.5 & 4828.1 & 0.360 \\
\hline $\mathrm{Dt}(\mathrm{m})$ & 0.382 & 0.387 & 1.92 \\
\hline$\mu_{\mathrm{d}(-)}$ & 1.87 & 1.78 & 4.82 \\
\hline $\mathrm{Sa}(\mathrm{Te})\left(\mathrm{m} / \mathrm{s}^{2}\right)$ & 4.53 & 0.259 & 0.241 \\
\hline $\mathrm{Sd}(\mathrm{Te})(\mathrm{m})$ & 0.256 & 33047 & 38254 \\
\hline $\mathrm{k}^{*}(\mathrm{kN} / \mathrm{m})$ & 33881 & 1.512 & 1.405 \\
\hline $\mathrm{T}^{*}(\mathrm{~s})$ & 1.493 & 2.82 & 2.83 \\
\hline $\mathrm{q}=\mathrm{Fe} / \mathrm{Fy} *(-)$ & 2.87 & & \\
\hline
\end{tabular}



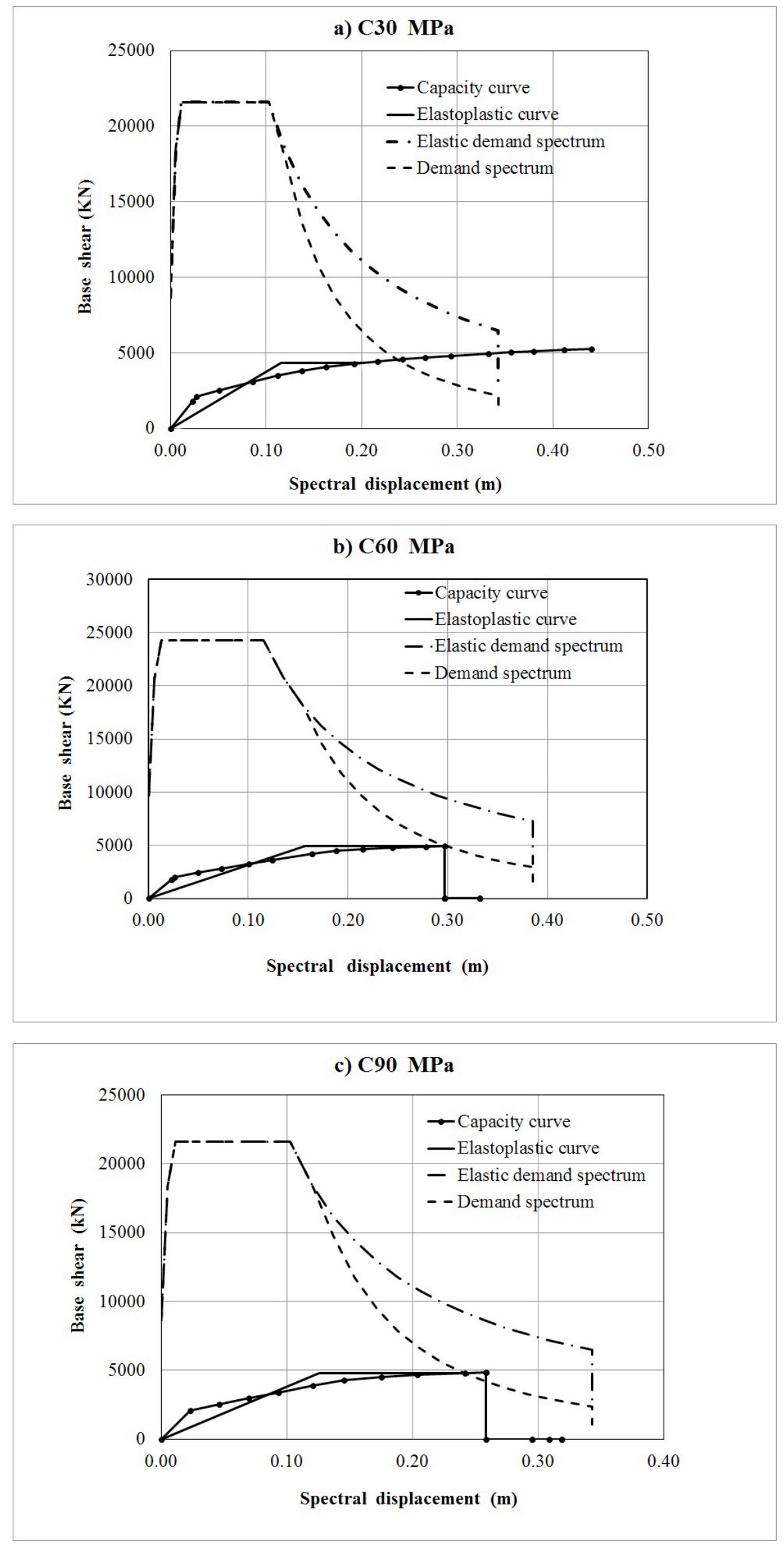

Fig. (9). Performance points of the three case studies in Spectral Displacements. 


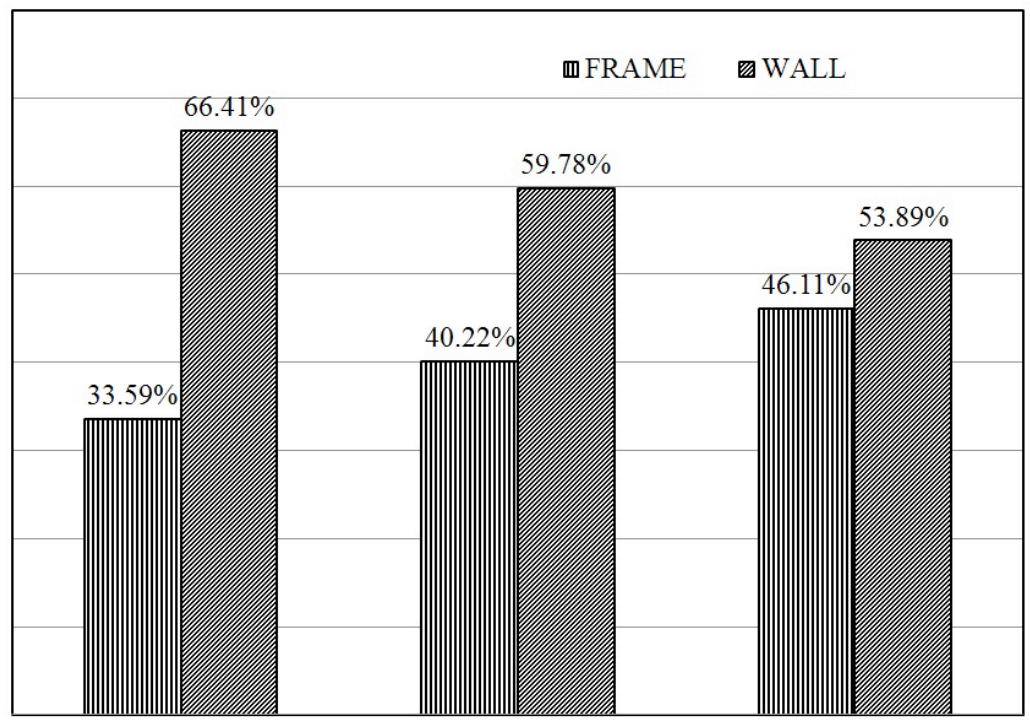

$30 \mathrm{MPa}$

$60 \mathrm{MPa}$

$90 \mathrm{MPa}$

Fig. (10). Relative base-shear between frame and wall for each case study.
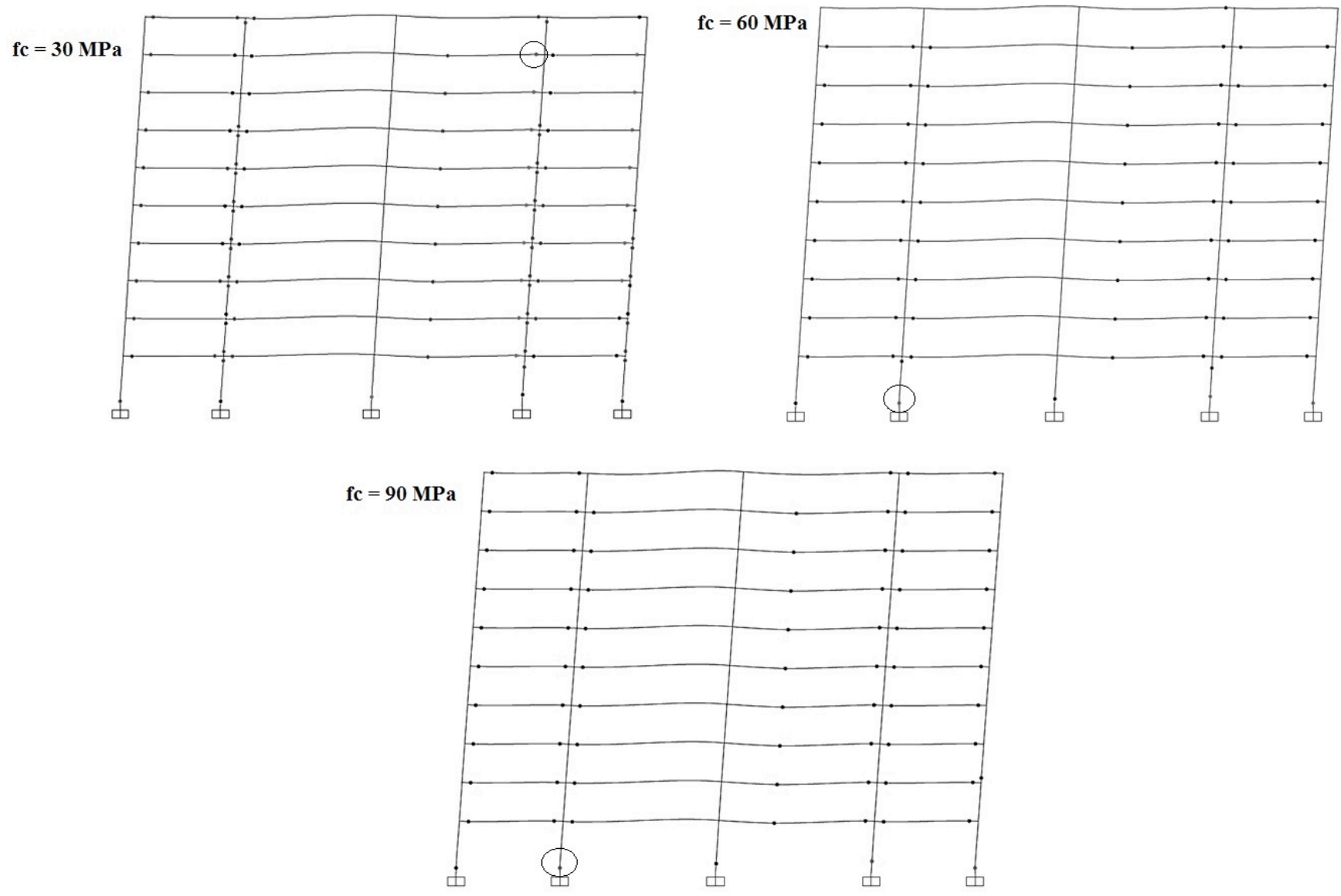

Fig. (11). Failure modes and critical element.

located at the beam of $9^{\text {th }}$ storey connecting the wall and the interior column. However, in the case of mid and high strength concrete, the failure mode is governed by reaching the failure of the 1 st storey column. In all three cases, this column experienced increments of axial forces during seismic action that tends to reduce ductility of the elements. Fig. (12) represents a typical evolution of the ductility capacity reduction of a wellconfined column as function of concrete strength and axial force ratio $(v)$. It is evidenced that the ductility reduction is considerably more significant for mid and high strength concrete than for the normal concrete case, which provides an explanation for the changing of first collapsing element. 


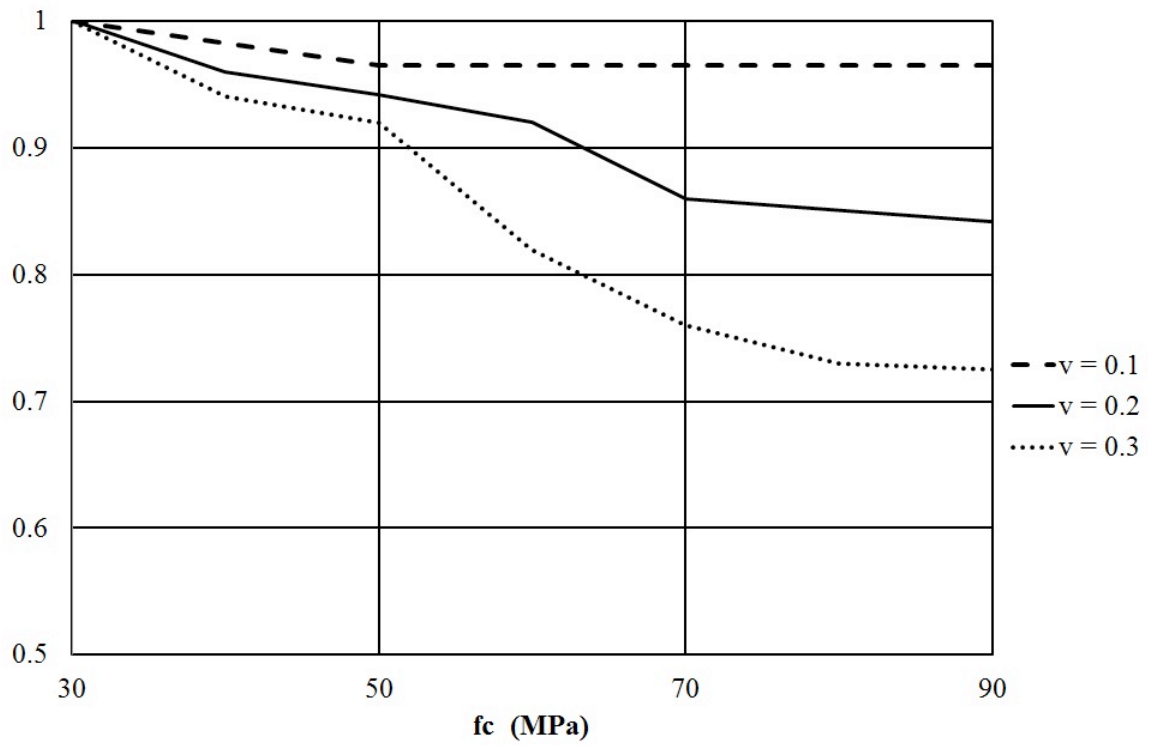

Fig. (12). Ductility reduction as function of axial force ratio $\left(v=\frac{N}{f_{c} A_{c}}\right)$ and concrete strength (MPa) in typical column.

\section{CONCLUSION}

The effects of using different concrete grades in the behavior of dual wall-frame systems were investigated. For this extent, a 10 stories system was design with concrete grades $30 \mathrm{MPa}, 60 \mathrm{MPa}$ and $90 \mathrm{MPa}$, as representative of normal, mid and high strength concrete. Design and used following displacement-based-design method and the Eurocodes provisions. Furthermore, the seismic performance was evaluated by means of a pushover; performance points were obtained using the Eurocode 8 approach.

In order to be able of conducting a realistic analysis, a numerical constitutive model for concrete, including confinement, was modified and compared against experimental data of high strength concrete up to $84 \mathrm{MPa}$. It was demonstrated that the model is bias towards the safety side with uniform distribution. Therefore, this model can be safely used for design and evaluation of existing building, although additional research is identified in order to provide a uniform bias in the deformation estimates of the confined concrete.

As concrete strength some overall ductility is observed. However, it was demonstrated that this does not necessarily mean an inadequate seismic capacity as it can be partially compensated by an increase of the over-strength factor. Adequate detailing for ductility is determinant considering the differences in the confined concrete characteristics.

Reduction of cross-section dimensions in this case study resulting from the use of higher concrete strength existed, although was modest. Dimensions reductions that are more significant should be expected in high-rise buildings or structures with significant gravity loads, such as parking lots and warehouses.

Displacement-based-design methodology was proved as an adequate approach, as it was capable to determine the required ductility in the HSC to be used in design. In this case, drift, displacements and strength demands were satisfied in a rather strict fashion, demonstrating the adequacy of the method. Nevertheless, changes in the failure mode was observed as in mid and high strength structures it was initiated by failure of bottom column because of its lower ductility induced by increase of axial force. In any case, this takes place for a larger displacement, i.e. seismic demand, than the design action and after yielding of previous elements; therefore, the design should be considered adequate. However, investigations on performance-based and capacity design can be carried out if this failure mode is to be avoided.

\section{CONFLICT OF INTEREST}

The authors confirm that this article content has no conflict of interest.

\section{ACKNOWLEDGEMENTS}

This research has been carried with the support of the Spanish Ministry of Economics and Competitiveness and the Europeans Funds for Regional Development (FEDER) through the of the research project "Performance-BasedDesign of partially prestressed concrete structures. Proposal of new design methodology, experimental verification and design criteria" (BIA2012-36848).

\section{REFERENCES}

[1] RPA-99/V. Règles parasismiques algèriennes. Algeria, 2003.

[2] EN-1998, "Eurocode 8: Design of structures for earthquake resistance", Comité Europeen de Normalisation, Brussels, 2004.

[3] J. B. Mander, M. J. N. Priestley, and R. Park, "Theoretical stressstrain model for confined concrete", Journal of Structural Engineering, vol. 29, no. 2, pp. 241-252, 1988.

[4] M. J. N. Priestley, G. M. Calvi, and M. J. Kowalsky, Displacement Based Seismic Design of Structures, IUSSPRESS, Pavia, Italy, 2007.

[5] NCSP-07, "Norma de construccion sismorresistente de puentes", Minsiterio de Fomento, España, 2007.

[6] ACI 341.3R-07, "Seismic evaluation and retrofit techniques for concrete bridges", American Concrete Institutive, USA, 2007. 
[7] M. Berry, and M. Eberhard, Performance Models for Flexural Damage in Reinforced Concrete Columns, Pacific Earthquake Engineering Research Center (PEER), University of California, Berkeley, 2003.

[8] ACI itg34R-07, "Report on Structural Design and Detailing for High-Strength Concrete in Moderate to High Seismic Applications", American Concrete Institute, USA, 2007.

[9] EN-1992, "Eurocode 2: Design of concrete structures", Comité Europeen de Normalisation, Brussels, 2004.

[10] U. Sharma, P. Bhargava, and S. Kaushik, "Behavior of confined high strength concrete columns under axial compression", Journal of Advanced Concrete Technology, Japan Concrete Institute, vol. 3, no. 2, pp. 267-281, 2005.

[11] E. Osorio, J. M. Bairan, and A. R. Mari, "Lateral behavior of concrete under uniaxial compressive cyclic loading", Materials and Structures, vol. 46, pp. 709-724, 2013.

[12] E. Wilson, and H. Habibula, "SAP2000: Static and dynamic finite element analysis of structures", Computers and Structures, Inc., Berkeley, California, 2010.

[13] J. M. Bairan, BCSEC: Beam-Column Section. Program for the Non-Linear Geometric and Material Analysis of Beam-Columns. Department of Construction Engineering, Universitat Politècnica de Catalunya, Barcelona, Spain, 2000.

(C) Bairán et al.; Licensee Bentham Open

This is an open access article licensed under the terms of the Creative Commons Attribution Non-Commercial License (http://creativecommons.org/licenses/ by-nc/3.0/) which permits unrestricted, non-commercial use, distribution and reproduction in any medium, provided the work is properly cited. 